\title{
Structure and properties of the directionally Mo-Si-B solidified alloy with the addition of lanthanum
}

\author{
M. Upatov' ${ }^{1}$ I. Bogomol ${ }^{1}$ \\ ${ }^{1}$ National Technical University of Ukraine "Igor Sikorsky Kyiv Polytechnic Institute" \\ Corresponding author. E-mail: nikitaupatov@gmail.com
}

Paper received 12.12.18; Accepted for publication 19.12.18.

\section{https://doi.org/10.31174/SEND-NT2018-186VI22-21}

\begin{abstract}
The directionally solidified Mo-17,5\% Si-8\%B-0,5\% $\mathrm{LaCl}_{3}$ (ат.\%) alloy was prepared by floating zone method. The microstructure of the alloy consists of $\mathrm{Mo}_{3} \mathrm{Si}$ matrix with predominantly fine-grained inclusions of the $\mathrm{Mo}_{5} \mathrm{SiB}_{2}(\mathrm{~T} 2)$ and molybdenum (Moss) phases and represents the alternation of the two- $\left(\mathrm{Mo}_{3} \mathrm{Si}-\mathrm{T} 2\right)$ and three-phase $\left(\mathrm{Moss}_{\mathrm{ss}}-\mathrm{Mo}_{3} \mathrm{Si}-\mathrm{T} 2\right)$ eutectics with periodic large $\mathrm{Moss}_{\text {ss. }}$ phase activations. The obtained values of integral microhardness and fracture toughness are 9.25 $\pm 0.5 \mathrm{GPa}, 14.32 \pm 0.6 \mathrm{MPa}$ $\mathrm{m}^{1 / 2}$, respectively. A solid protective oxide coating was obtained due to 10 hours air holding at $1030^{\circ} \mathrm{C}$.
\end{abstract}

Keywords: floating zone method, eutectic, oxidation, borosilicate coat.

Introduction. Last years the scientific interest to Mo-SiB alloys, which can become potential substitutes for nickel superalloys for manufacturing of turbine blades and other high-temperature units, was considerably increased, because they have higher operating temperatures and can significantly increase of energy efficiency of gas turbine engines.

Literature review. The alloys of $\mathrm{Mo}-\mathrm{Si}-\mathrm{B}$ system consisting of a molybdenum solid solution $\left(\mathrm{Mo}_{\mathrm{ss}}\right)$ and two other intermediate $\mathrm{Mo}_{5} \mathrm{SiB}_{2}$ (T2) and $\mathrm{Mo}_{3} \mathrm{Si}$ (A15) phases uniformly distributed in the microstructure show attractive mechanical and oxidizing properties at temperatures above $1100^{\circ} \mathrm{C}$ [1]. This system became the subject of close attention, since the temperature of application may exceed the temperature of the application of super-alloys based on nickel [2]. The Mo-Si-B alloys has excellent oxidation resistance above $1100^{\circ} \mathrm{C}$, due to the formation of a low viscose borosilicate coating that covers the surface of the material and provides protection against further oxidation [3]. However, alloys of the Mo$\mathrm{Si}$-B system show a low resistance to oxidation in the range $650-900{ }^{\circ} \mathrm{C}$ [4] when the borosilicate coating is not formed yet, which causes the formation and evaporation of $\mathrm{MoO}_{3}$. Recent studies [5,6] have shown that the addition of rare earth elements improves both the oxidation resistance of such materials over a wide range of temperatures and their mechanical characteristics.

The current task is to prepare the alloy of Mo-Si-B system with optimal microstructure, mechanical properties and resistance to oxidation $[1,7]$. Using of directional crystallization allows to efficient control of structure and properties due to variation of technological parameters of growing, which enables to control both oxidative and mechanical properties [8].

Objective. Therefore, the purpose of this work was to study the influence of addition of lanthanum on the structure and properties of directionally solidified Mo-17.5 (at.\%) Si-8 (at.\%) B alloy.

Experimental details. Directionally solidified Mo17,5 at. $\%$ Si-8 at.\% B alloy with an admixture of 0.5 atomic $\%$ of $\mathrm{LaCl}_{3}$ was prepared by floating zone melting of nonsintered powdered rods. The molybdenum, silicon, boron and lanthanum chloride powders with a purity of $99.95 \%, 99.9 \%, 98 \%$, and $99 \%$, respectively, were used as starting materials. The average particle size of molybdenum powder was $3.4 \mu \mathrm{m}$, silicon powder - $1.2 \mu \mathrm{m}$, boron powder $-0.5 \mu \mathrm{m}$, lanthanum chloride powder - 2 $\mu \mathrm{m}$. A mixture of powders was prepared by 10 -fold wiping through a sieve with cells measuring 50 microns. As a plasticizer the $2.5 \%$ aqueous solution of polyvinyl alcohol was used. Long-length billets with a diameter of 10 $\mathrm{mm}$ and a length of $145 \mathrm{~mm}$ were pressed on a hydraulic press under a pressure of $50 \mathrm{MPa}$ and dried in a vacuum oven at $100^{\circ} \mathrm{C}$. Zone melting of samples was carried out in the high-frequency "Crystal 206" machine with induction heater.

The microstructure of the samples was studied using a scanning electron microscope (SEM) "SELMI PEM 106". X-ray diffraction analysis was carried out at the "Rigaku Ultima IV" diffractometer. Micromechanical properties were investigated using the microhardness tester MHV-1000. Studies on oxidation resistance were conducted on a Q-1000 derivatograph to $1030{ }^{\circ} \mathrm{C}$ with a heating rate of $20^{\circ} \mathrm{C} / \mathrm{min}$ on air atmosphere for 10 hours.

Results and discussion. The investigation of the microstructure of the directionally solidified Mo-17,5Si-8B$0,5 \mathrm{LaCl}_{3}$ alloy by SEM showed the presence of three phases: $\mathrm{Mo}_{3} \mathrm{Si}$ gray matrix, mainly small dark gray inclusions of $\mathrm{Mo}_{5} \mathrm{SiB}_{2}$ (T2) and light particles of a solid solution of molybdenum (Moss) (Fig. 1).

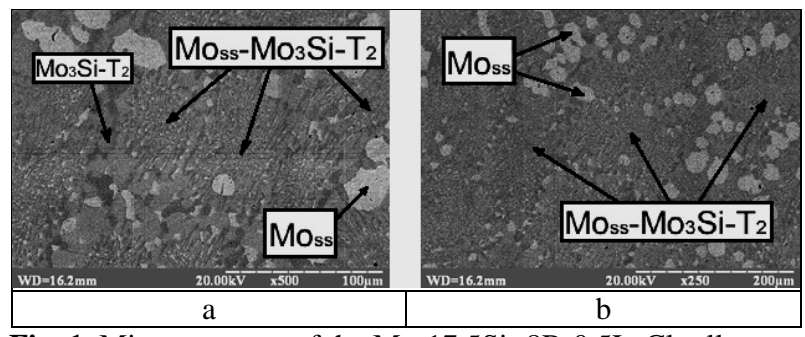

Fig. 1. Microstructure of the Mo-17,5Si- $8 \mathrm{~B}-0,5 \mathrm{LaCl}_{3}$ alloy: a $\mathrm{x} 500 ; \mathrm{b}-\mathrm{x} 250$

Thus, the microstructure of the observed material is represented by the alternation of the two $\left(\mathrm{Mo}_{3} \mathrm{Si}-\mathrm{T} 2\right)$ and three-phase $\left(\mathrm{Mo}_{\mathrm{ss}}-\mathrm{Mo}_{3} \mathrm{Si}-\mathrm{T} 2\right)$ eutectic with periodic large inclusions of the $\mathrm{Mo}_{\mathrm{ss}}$ phase.

The structure in the center of the sample is distributed rather uniformly, but closer to the periphery there is a conventional border of division, after which the structure has a clearly directional character. The molybdenum solid solution and the T2 phase were crystallized in the material as dendritic crystals. It is observed the tendency of the dendritic branches to the side borders of the sample due to the temperature gradient between the center and the edge of the crystallization front. The exclusive feature of the alloy is the fine-grained nature of the structure (Fig 2). 


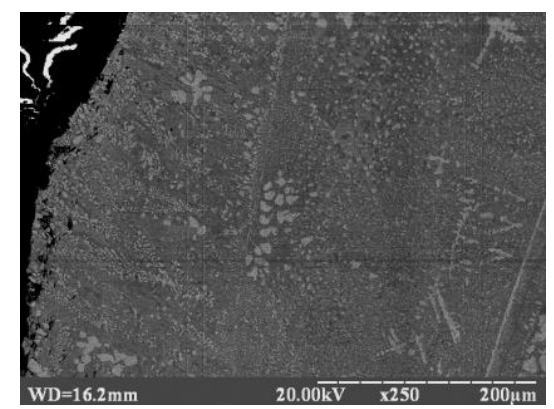

Fig. 2. Macrostructure of the Mo- $17,5 \mathrm{Si}-8 \mathrm{~B}-0,5 \mathrm{LaCl}_{3}$ alloy from the center to the edge of the sample

The X-ray phase analysis of the Mo-17,5Si- 8B$0,5 \mathrm{LaCl}_{3}$ alloy confirmed the presence of only 3 phases: molybdenum solid solution and both intermetallic phases: $\mathrm{Mo}_{3} \mathrm{Si}$ and $\mathrm{Mo}_{5} \mathrm{SiB}_{2}$ (Fig. 3).

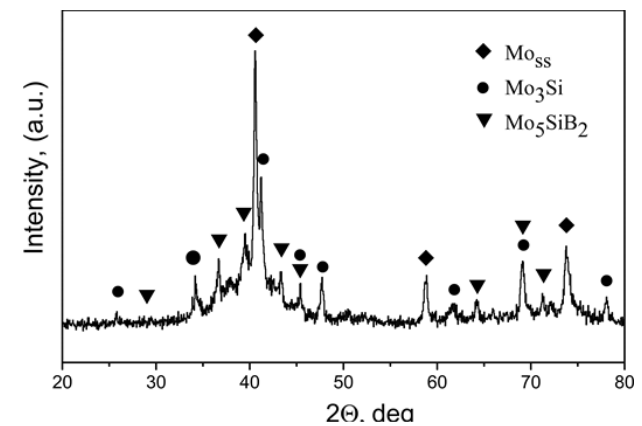

Fig. 3. X-ray diffractogram of the Mo-17,5Si- $8 \mathrm{~B}-0,5 \mathrm{LaCl}_{3}$ alloy

By the Vickers indentation method the values of integral microhardness and fracture toughness of the alloy as $9,25 \pm 0.5 \mathrm{GPa}$ and $14,32 \pm 0.6 \mathrm{MPa} \mathrm{m}^{1 / 2}$ were obtained. Such values of the micromechanical properties exceed the values previously obtained for the Mo-17,5Si-8B alloy [8] and are explained by a uniform fine-grained eutectic structure of the prepared material.

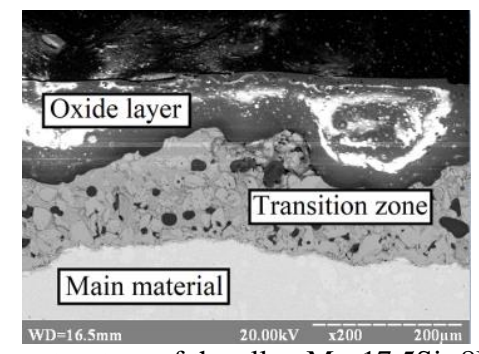

Fig. 4. Macrostructure of the alloy Mo-17,5Si- $8 \mathrm{~B}-0,5 \mathrm{LaCl} 3$ after oxidation.

The investigation of oxidation behavior of the material showed that the sample exposure for 10 hours at a temperature of $1030{ }^{\circ} \mathrm{C}$ on air atmosphere leads to the formation of the dense protective coating (Fig. 4). Three characteristic zones are distinguished on the microstructure: the oxide layer, the transition zone and the main material. According to [3], the protective layer is a borosilicate $\mathrm{SiO}_{2}-\mathrm{B}_{2} \mathrm{O}_{3}$ coating and the transition zone consists of two phases: $\mathrm{MoO}_{2}$ and $\mathrm{Mo}$ grains. The formation of $\mathrm{MoO}_{2}$ and Mo grains may indicate a low partial pressure of oxygen at the interface between the oxide layer and the transition zone, showing the presence of a stable protective coating in the resulting material.

Conclusions. Thus, the directionally solidified eutectic alloy is prepared by floating zone melting of nonsintered powdered rods of $\mathrm{Mo}-17,5 \mathrm{Si}-8 \mathrm{~B}-0,5 \mathrm{LaCl}_{3}$. The microstructure of the alloy consists of the $\mathrm{Mo}_{3} \mathrm{Si}$ matrix with predominantly fine-grained inclusions of the $\mathrm{Mo}_{5} \mathrm{SiB}_{2}$ (T2) and molybdenum solid solution $\left(\mathrm{Mo}_{\mathrm{ss}}\right)$ phases and represents the alternation of the two- $\left(\mathrm{Mo}_{3} \mathrm{Si}-\mathrm{T} 2\right)$ and three-phase $\left(\mathrm{Mo}_{\mathrm{ss}}-\mathrm{Mo}_{3} \mathrm{Si}-\mathrm{T} 2\right)$ eutectic with periodic large $\mathrm{Mo}_{\text {ss }}$ phase activations. The values of integral microhardness and fracture toughness of $9.25 \pm 0.5 \mathrm{GPa}$ and $14.32 \pm 0.6 \mathrm{MPa} \mathrm{m}{ }^{1 / 2}$, respectively, exceed the value for non-alloyed Mo-17,5Si-8B alloy. The investigation of oxidation behavior of the material showed that the sample exposure for 10 hours at a temperature of $1030{ }^{\circ} \mathrm{C}$ on air atmosphere leads to the formation of the dense protective coating.

\section{REFERENCES}

1. Dimiduk D. M. Mo-Si-B alloys: Developing a revolutionary turbine-engine material / D. M. Dimiduk, J. H. Perepezko. // MRS Bulletin. - 2003. - №28. - C. 639-645.

2. Wen S. H. Improvement of oxidation resistance of a Mo62Si-5B (at.\%) alloy at $1250{ }^{\circ} \mathrm{C}$ and $1350{ }^{\circ} \mathrm{C}$ via an in situ pre-formed $\mathrm{SiO}_{2}$ fabricated by spark plasma sintering / S. H. Wen, C. G. Zhou, J. B. Sha. // Corrosion Science. - 2017. №127. - C. 175-185.

3. Transient oxidation of Mo-Si-B alloys: Effect of the microstructure size scale / F. A.Rioult, S. D. Imhoff, R. Sakidja, J. H. Perepezko. // Materials Science and Engineering. - 2009. - №57. - C. 4600-4613.

4. Sharma Paswan. Isothermal oxidation behaviour of Mo-Si-B and $\mathrm{Mo}-\mathrm{Si}-\mathrm{B}-\mathrm{Al}$ alloys in the temperature range of $400-800$ ${ }^{\circ}$ C / Sharma Paswan, R. Mitra, S. K. Roy. // Materials Science and Engineering. - 2006. - №424. - C. 251-265.
5. Ductility of Mo-12Si-8.5B alloys doped with lanthanum oxide by the liquid-liquid doping method / Wenhu Li, Guojun Zhang, Shixiong Wang та ін.]. // Journal of Alloys and Compounds. - 2015. - №642. - C. 34-39.

6. Microstructural and micro-mechanical properties of Mo-Si-B alloyed with Y and La / [S. Majumdar, A. Kumar, D. Schliephake]. // Materials Science \& Engineering A. - 2013. №573. - C. 257-263.

7. Lemberg J.A., Ritchie R.O. Mo-Si-B alloys for ultrahightemperature structural applications // Advanced Materials. 2012. —24, № 26. - P. 3445-3480.

8. Microstructure and creep properties of a near-eutectic directionally solidified multiphase Mo-Si-B alloy / [G. Hasemann, I. Bogomol, D. Schliephake and other.]. // Intermetallics. 2014. - №48. - C. 28-33. 